\title{
The impact of computer based training on technical training in industry*
}

\author{
David M. Goldsmith \\ Educational Systems Manager \\ Australian Industrial Publications Pty Ltd
}

\begin{abstract}
There is growing acceptance in industry of Computer Based Training (CBT) as an appropriate medium for technical training. Few CBT systems are designed to meet the flexible instructional design needs or simulation requirements of such training, or are capable in the longer term of adaption to the use of Artificial Intelligence (AI) principles, Serious trainers and educators have had to re-examine system specifications and capabilities before embarking further on the path to automated training.
\end{abstract}

\section{Historical introduction}

Computer Based Training had its beginnings in the work carried out at the University of Illinois leading to the development of the product known as PLATO and marketed internationally by the Control Data Institute. CBT in the early 1960s simply used the ability of programmers to manipulate words using a computer. Text based courseware dominated the consciousness of developers with the result that much of the earlier work in CBT, and regrettably too much recent courseware, has been little more than computer controlled page turning. Courseware too frequently became a series of text statements, or occasionally situational scenarios, augmented by a series of true-false or multi-choice questions. Regrettably too, because much of the early courseware was hard-coded by

* This paper was presented at the EdTech'88 Conference in September 1988 [http:// ascilite.org.au/aset-archives/confs/edtech88/edtech88_contents.html], but was not available in time to be included with the Conference papers. Copies of the papers - Designing for Learning in Industry and Education - are available from AJET Publications for $\$ 20.00$ each (\$30.00 foreign), including postage. 
programmers, little emphasis was placed upon instructional design processes appropriate to the new medium and much courseware lacked appropriate educational structure. The result was rejection of CBT by most serious educators and trainers.

By the late 1970s a variety of menu driven authoring systems began to appear. At last courseware could be written by non-computer literate trainers, but too many of the systems provided only very limited educational styles and only the primitive graphics that could be generated using the keyboard. The early 1980s saw a growth in the recognition and availability of computer graphic images as being central to good communication in CBT but in spite of many outstanding advances in "paint packages" and the flexibility of PCs even the most respected writers in commercial CBT rejected graphics as being "too expensive" and not worthy of serious consideration. Gloria Gery (1987) states:

"You must make decisions about the value added by graphics to the educational experience. But graphics are expensive to generate and require considerable storage."

Gery is not here writing of technically oriented courseware only of commercial courseware. (When personally challenged on this point Gery admitted that her statement was sweeping and that she had had little contact with good quality graphic-centred authoring systems or languages.)

\section{CBT and Technical Training}

Because of the emphasis on the printed word much of the CBT developed for technical training needs proved unacceptable because of:

- an emphasis on readability inappropriate to the technical task or trainees,

- a requirement to use a keyboard for trainee interaction with the system, the keyboard creating a real barrier for most trainees, and

- the concentration of courseware demanding and testing short term recall rather than conceptual understanding on the one hand or sequential operator processes on the other.

It has only been the appearance of graphics based authoring languages, or some more expansive authoring systems, that has allowed CBT to begin to take its rightful place as a cost-effective, stimulating training medium in the area of technical training in industry. Further the use of pointer devices such as a mouse or a touch-sensitive screen avoid the confrontation frequently attributable to keyboard interaction. 


\section{CBT and Instructional Design}

The lack of expertise in instructional design and the increased effort to structure effective training satisfactorily using CBT has further delayed acceptance. In spite of the excellent work emanating from R. Gagne (1974), Gagne and Briggs (1979) and associates at the Florida State University, and at a few similar institutions, little has genuinely permeated the Australian training industry. Certainly our Defence Services base much of their training on a Gagne-oriented "Systems Approach" to training development and this is readily identifiable in courses produced in their Schools of Training Technology. These same principles have not been transported easily into CBT development although there is ample reference to these needs in the writings of Gagne, H.F. O'Neill et. al (1979), G. Kearsley (1978, 1982, 1983 and 1985) and others.

Internationally it is largely the recognition of graphics-based authoring languages that allow total flexibility of training development and instructional design that have led to some recognition of quality oriented CBT. One such product is AIP CourseMaster, the authoring language developed by Australian Industrial Publications in Melbourne, and now used by the Royal Australian Navy, several Electricity Commissions, major manufacturers such as BHP, and several mining companies. CourseMaster is just finding its place in a number of educational institutions and is gaining attention because of its ease of use for the development of training courseware and flexibility to allow appropriate instructional design for technical training. Further, to provide motivation and satisfaction in the training process, the trainee must feel that pace and direction are genuinely under personal control and this too takes effort on the part of authors. Interactivity which is not simply menu selection or response to questioning is difficult to achieve.

\section{CBT used in Technical Training}

Where CBT has been used in technical training in industry in Australia it is sourced largely from USA and is too frequently of a testing type only. Some good materials are presently used in the electricity/electronics field, although much is now outdated and lacks sufficient relevance to Australian curricula. Much of the courseware developed locally for use in the automotive industry is of low educational quality and there is little or nothing relating to hydraulics. Too frequently CBT materials have been directly transcribed from textbook or classroom modes without real recognition of the differences of media involved. In the last two or three years interactive videodiscs have started to have an impact on some areas of technical training but too many are presentations rather than interactive teaching sequences and simply incorporate disc technology where earlier the presentation was tape-based. There is much to be done if CBT is to achieve the role that it could have in technical training. 


\section{CBT and Artificial Intelligence}

As we move closer to the end of the 1980s so more frequently are we learning of developments in the field of Artificial Intelligence (AI) and in particular of the use of $\mathrm{Al}$ principles in the development of Expert Systems. For any educational or training process to have the potential for integration with an expert system and control by it, there is necessarily extensive analysis of the learning objects to be incorporated.

Authoring techniques developed within the CourseMaster authoring language allow for the definition of an object as containing subject material and a presentation system:

\section{OBJECT}

\begin{tabular}{|c|}
\hline Subject material \\
Presentation system
\end{tabular}

Through CourseMaster authoring the author provides pointers to:

- general help objects,

- special help objects, and

- indexed help objects.

The author also provides pointers to:

- test objects in which items are randomised,

- topic menu objects,

- master menu objects, and

- re-start objects.

All objects are author set and system modified, but provide the student with apparent control of the learning process.

In this way very sophisticated system directed courseware is provided emulating totally the inference engine of an expert system.

Typically it is essential that developers have the ability to identify, organise and develop suitably structured objects and this in itself demands a level of expertise not common amongst CBT developers. Further in the high level modularisation required for object manipulation the authoring language used must allow the author to provide clear but incrementable identity to each object and the ability to recognise not only the first use but also all subsequent uses of each module in relation to others.

CourseMaster is not an expert system per se in that it does not generate a knowledge base. By careful identification of objects and the accumulation of objects into concept modules by the structured use of global, internal 
and scratch registers, CourseMaster can be structured to emulate an expert system. When this capability is associated with wide ranging emulation and simulation functions, CourseMaster can be used to provide stimulating training which with care can approach computer based education rather than simply CBT.

\section{CBT Development For Industry}

The development of CBT courseware for industry demands as high a level of instructional design as may be appropriate to any other training development. The process of providing courseware for clients must be well structured and have built into it the highest levels of quality assurance. The phases of development are likely to include at least:

- a needs analysis leading to a course aim;

- a job task analysis to identify the required elements of the course content;

- a clear requirement specification for client approval which will include statements of skill, performance, procedural and behavioural objectives and the methods by which their achievements will be evaluated;

- a statement of assessment processes and pass requirements;

- a project plan against which quality assurance (Q.A.) can be assessed; detailed instructional design; scripting, flowcharting and storyboarding, each of which has Q.A. approval and client acceptance.

Once authoring/coding has been completed, the Q.A. manager will institute an agreed validation process prior to delivery for field testing and final editing.

Clearly, if the process of development of training in any situation follows this type of structure, there is a chance that the resulting product will achieve what is expected of it. When this is coupled with the modularisation and object identity demanded for expert system interface, the development process is clearly a non-trivial one. To achieve these attributes successfully, a very flexible authoring language is required. Such a tool for the development of high quality CBT is AIP CourseMaster.

\section{Summary}

Early efforts to introduce CBT for technical training were largely unsuccessful because much of the courseware was text-centred and lacked educational quality. Industry has been slow to accept the importance of good quality computer graphics to support training presentation. Equally poor instructional design and the lack of flexibility available from authoring systems has further delayed acceptance of CBT for technical training. To achieve appropriate modularisation and object definition 
needed for expert system interface appropriate educational skills are essential. Without the availability of a flexible authoring language educators and trainers are unlikely to achieve acceptable standards for CBT. AIP CourseMaster is an authoring language which has the necessary attributes to provide the basis for the development of high quality, graphic centred CBT courseware which will uplift the quality of CBT used for technical training in industry.

\section{References}

Gagne, R. and Briggs, L. (1974). Principles of Instructional Design. Holt Reinhart, USA.

Gagne, R. (1979). The Conditions of Learning. Holt Reinhart, USA.

Gery, G. (1987). Making CRT Happen. Weingarten, USA.

Kearsley, G. (1978). The Relevance of AI Research to CAI. Journal of Educational Technology Systems, 6(1), 229-250.

Kearsley, G. (1982a). Authoring Systems in Computer Based Education. Communications of the ACM, July, 429-437.

Kearsley, G. (1983). Computer Based Training. Addison Wesley.

Kearsley, G. (1985). Training for Tomorrow. Addison Wesley.

O'Neill, H. F., et al.(1979). Issues in Instructional System Development. Academic Press, New York.

Please cite as: Goldsmith, D. M. (1988). The impact of computer based training on technical training in industry. Australian Journal of Educational Technology, 4(2), 103-108.

http: / / www.ascilite.org.au/ajet/ajet4/goldsmith.html 